www.jmscr.igmpublication.org

Impact Factor 5.84

Index Copernicus Value: 83.27

ISSN (e)-2347-176x ISSN (p) 2455-0450

crossref DOI: _https://dx.doi.org/10.18535/jmscr/v5i8.10

Journal Of Medical Science And Clinical Research

\title{
A Comparative study between Retroperitoneoscopic and open Dismembered Pyeloplasty in the Management of Ureteropelvic Junction Obstruction
}

\author{
Authors \\ Venugopal G ${ }^{1}$, Manu M K ${ }^{2}$, Vasantharaja $R^{3}$, Subeesh $P^{4}$, Priyabrata Das ${ }^{5}$, Libu G $K^{6}$ \\ ${ }^{1}$ Professor, Department of Urology, Trivandrum Medical College, Kerala, India \\ ${ }^{2}$ Additional Professor, Department of Urology, Trivandrum Medical College, Kerala, India \\ ${ }^{3,4,5}$ Senior Resident, Department of Urology, Trivandrum Medical College, Kerala, India \\ ${ }^{6}$ Assistant Professor, Department of Community Medicine, Trivandrum Medical College, Kerala, India \\ Corresponding author
}

Manu M K

Additional Professor, Dept of Urology, Trivandrum Medical College, Trivandrum, Kerala- 695011 India

Email:drmanumk@gmail.com

Mobile No: +91 9495746829, Landline No: +914712458617

\begin{abstract}
Objectives: To evaluate Retroperitoneoscopic dismembered Pyeloplasty (RDP) for Ureteropelvic junction obstruction (UPJO) and compare with Open dismembered Pyeloplasty (ODP) in terms of perioperative outcomes and success rate.

Materials and Methods: We analysed perioperative outcomes and success rates among the 150 cases of ODP and 150 cases of RDP performed from June 2011 to December 2016. Perioperative outcomes were Blood Loss, Analgesia Requirement, incidence of Paralytic ileus, incidence of Atelectasis, Convalescence, day of drain removal, operative time, Hospital Stay and Success Rate. Patients were followed up clinically and radiologically with IVP \& Renogram on $3^{\text {rd }}$ month and by Renogram on 12th month and yearly thereafter. Association between variables were compared using Student's t test and Chi Square Test for calculating significance.

Results: Analgesic requirement in terms of morphine equalents 34.55 vs $85.10 \mathrm{mg}$ (RDP vs ODP). Mean day of starting oral intake 1.22 vs. 2.09 days (RDP vs ODP). Mean day of ambulation 1.17 vs. 2.09 days (RDP vs ODP). Mean day of drain removal 2.47 vs. 3.11 days (RDP vs ODP). Mean day of discharge 3.43 vs. 7.18 days (RDP vs ODP). Post-op atelectasis was seen in 10\% of ODP and 2\% in RDP. Mean operative time were 123.79 vs 135.87 minutes (RDP vs ODP). Success rates were comparable.

Conclusion: Retroperitoneoscopic Dismembered Pyeloplasty compared to Open Dismembered Pyeloplasty has the advantage of shorter hospital stay, reduced analgesia requirement, reduced incidence of atelectasis, early convalescence and equal success rate proving to be the Gold Standard procedure in management of UPJO.
\end{abstract}

Keywords: Retroperitoneoscopy, Pyeloplasty, Ureteropelvic junction obstruction. 


\section{Introduction}

Open dismembered Pyeloplasty (ODP) is considered to be the gold standard procedure for the management of ureteropelvic junction obstruction (UPJO), with high success rate more than $90 \%{ }^{[1]}$. Laparoscopic pyeloplasty was first described by Schuessler et al ${ }^{[2]}$. It is globally practiced and widely accepted minimally invasive surgery for ureteropelvic junction obstruction ${ }^{[3]}$. It has decreased morbidity similar to endoscopic approaches with comparable success rates to the conventional open approach ${ }^{[4]}$. Due to transperitoneal approach of this procedure, certain bowel related complications were seen postoperatively. Janetschek et al, first described retroperitoneoscopic dismembered Pyeloplasty (RDP) and found it was complicated to be considered as a standard procedure ${ }^{[5]}$. Retroperitoneoscopic approach has a limited working space for instrument handling and intracorporeal suturing but direct access to the ureteropelvic regions was possible $\mathrm{e}^{[3] ;[6-8]}$. However, over a period of time retroperitoneoscopic dismembered Pyeloplasty has evolved with various technical changes based on surgeon's experience on the procedure.

Currently, retroperitoneoscopic dismembered Pyeloplasty is moving towards the consideration of gold standard procedure, minimizing its limitations, technical complications and huge success rate comparable to open dismembered Pyeloplasty. Based on various recent studies, Retroperitoneoscopic dismembered Pyeloplasty is considered to be safe, less morbid and shorter convalescence ${ }^{[9-11]}$. In this study, we are retrospectively comparing the morbidity, perioperative outcomes and success rate between open dismembered Pyeloplasty and Retroperitoneoscopic dismembered Pyeloplasty performed by a single surgeon.

\section{Materials and Methods \\ Study population}

The study population was 150 patients who underwent Retroperitoneoscopic dismembered Pyeloplasty and 150 patients who underwent Open dismembered Pyeloplasty during the period between June 2011 and December 2016. All patients had been diagnosed and confirmed preoperatively to have ureteropelvic junction obstruction based on imaging and diuretic renography. All the cases were conducted in a single tertiary care center.

\section{Methods}

Basic demographic, clinical and radiological details were analyzed for the study population. Patients were subjected to thorough pre operative anesthetic check up and optimized for surgery. All Retroperitoneoscopic dismembered Pyeloplasty were performed using a four port balloon dissecting technique as previously with few modifications as described below ${ }^{[12]}$. Under general anesthesia patient was placed in full flank position (as shown in figure 1). Camera port inserted using open technique and retroperitoneal space created using Gaur's balloon technique as described previously ${ }^{[13]}$ We used a custom made balloon using excised glove finger tied to 14 French suction catheter (as shown in figure 2). We placed the custom made balloon in retroperitoneal space, inflated with 500 $\mathrm{ml}$ normal saline left in place for 10 minutes. Following camera port, other ports were serially inserted (as shown in figure 1). Proximal Ureter and renal pelvis dissected. Underlying cause of obstruction (stenosis, crossing vessel) identified and dealt with accordingly. Renal pelvis incised in its most dependent part suitable for funnel shaped anastomosis. The ureter was held in position while incising pelvis followed by dismembering and spatulation of ureter. 3-0 or 4-0 polyglactin suture material was used to suture apparent posterior layer initially in continuous fashion followed by antegrade Double $\mathrm{J}$ pigtail stent placement across anastomosis. Excess redundant pelvic tissue was excised and anterior layer sutured in similar fashion. The steps of Retroperitoneoscopic dismembered pyeloplasty are illustrated in Figure 3 (a-h). Closed suction drain was placed through the mid axillary line port before closure. All the Retroperitoneoscopic dismembered Pyeloplasty were performed by a single surgeon. 


\section{JMSCR Vol||05||Issue||08||Page 26041-26047||August}

Figure 1: Full flank position and port placement for retroperitoneoscopic pyeloplasty

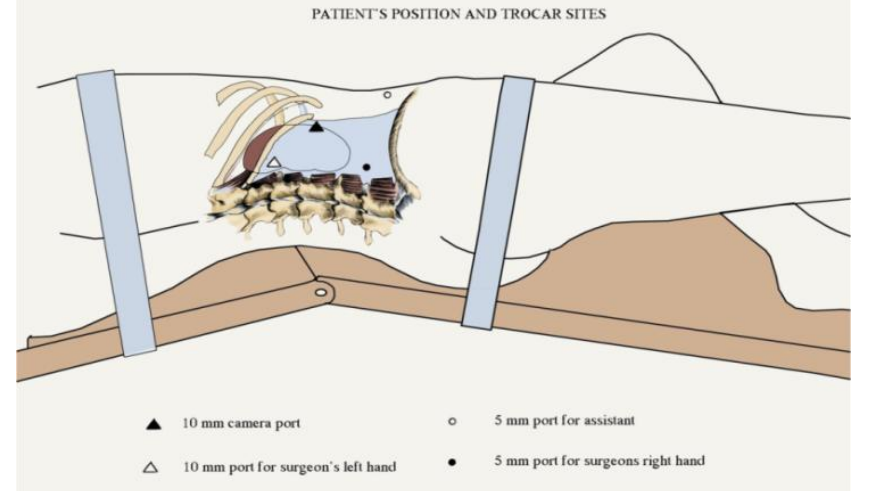

Figure 2: Custom made balloon for retroperitoneal space creation

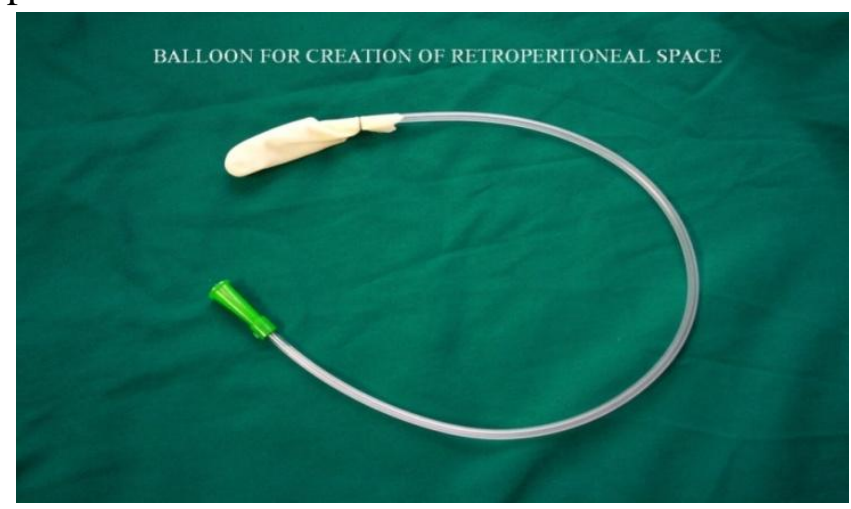

Open dismembered Pyeloplasty were performed by multiple surgeons of the same department using standard retroperitoneal approach through $11^{\text {th }}$ rib tip excision ${ }^{[14]}$.

Perioperative management was carried out in similar fashion in both groups to facilitate better comparison. Third generation cephalosporin was used as prophylactic antibiotics. Routine analgesic usage was kept similar in both groups and excess doses given as on patient controlled basis. Drain was removed when the output was less than $10 \mathrm{ml}$ and followed by Foleys catheter removal. The ureteral stent was removed 4 weeks postoperatively. Study parameters included were perioperative outcomes like Blood Loss, Analgesia Requirement, Incidence of Paralytic ileus, Incidence of Atelectasis, Convalescence, Day of drain removal, Operative time, Hospital Stay, Success Rate etc. Patients were followed up clinically and radiologically with IVP $\&$ Renogram on $3^{\text {rd }}$ month and by Renogram on $12^{\text {th }}$ month and yearly thereafter.

\section{Statistical Analysis}

Data was entered according to the variables onto spreadsheets of Microsoft Office Excel 2007 and the variables were analyzed using standard analytical techniques. The associations between study variables were analyzed using Chi-square test and student's t test. ' $p$ ' values $<0.05$ were considered significant.

Figure 3 Steps in Retroperitoneoscopic Pyeloplasty

a) Renal pelvic incision renal

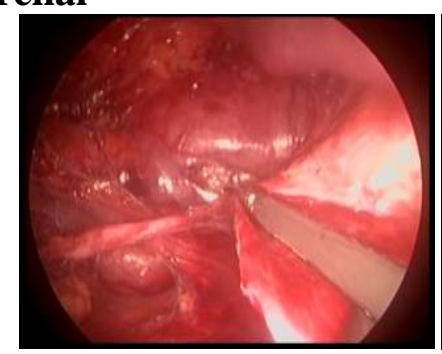

c) Spatulation of ureter wall

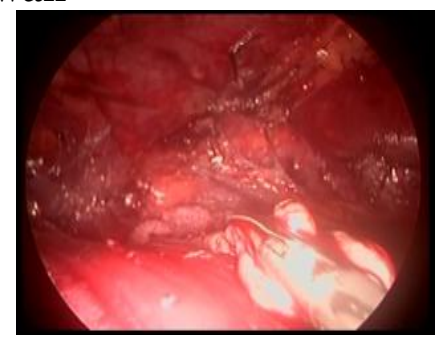

e) Excision of excess placement

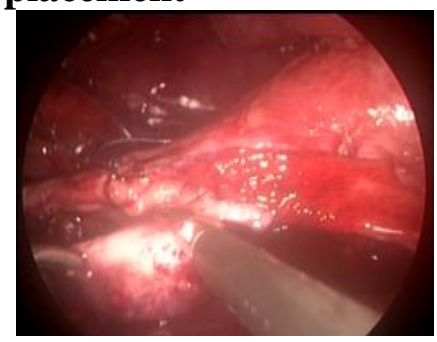

g) Suturing of posterior $h$ )Ureteropelvic junction wall of ureter

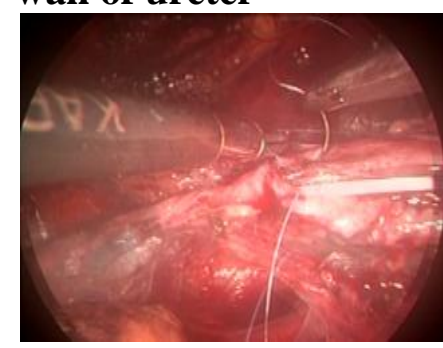

b) Dismembering of pelvis

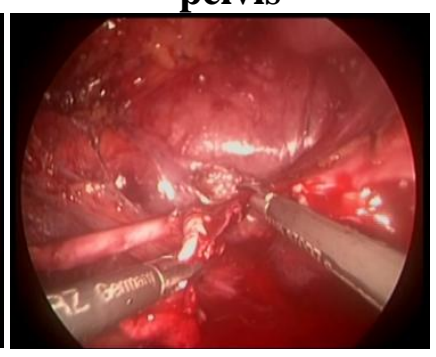

d) Suturing of anterior of ureter

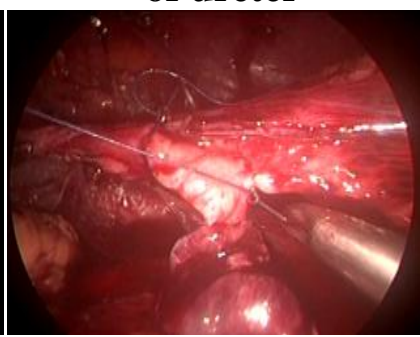

f) Antegrade stent redundant pelvis

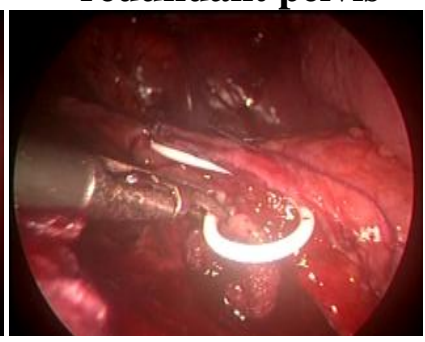
after recontruction 


\section{Results}

Demographic data comparing Retroperitoneoscopic and Open approach were shown in Table 1. Mean patient ages were 28.19 years in Retroperitoneoscopic approach compared to 28.31 years in Open approach. Out of 150 patients 91 were males and 59 were females in RDP group. Out of 150 patients 87 were males and 63 were females in ODP group. Out of 150 patients 80 had left sided disease and 70 had right sided disease in RDP group. Out of 150 patients 93 had left sided disease and 57 had right sided disease in ODP group. The percentage of cases with crossing vessel as underlying cause was $50.7 \quad(76 / 150)$ in Retroperitoneoscopic approach and 40 (60/150) in Open approach.

Table 1 Comparison of demographic data between Retroperitoneoscopic dismembered Pyeloplasty (RDP) group and Open dismembered Pyeloplasty (ODP) group.

\begin{tabular}{|lcc|}
\hline & RDP group & ODP group \\
\hline Number of patients $(\mathrm{n})$ & 150 & 150 \\
Patient age-in years (mean \pm & $28.19 \pm 10.12$ & $28.31 \pm 6.16$ \\
Standard deviation) & & \\
Male/Female patients & $91 / 59$ & $87 / 63$ \\
Left/Right sided disease & $80 / 70$ & $93 / 57$ \\
\hline
\end{tabular}

Perioperative data comparing Retroperitoneoscopic and Open approach were shown in Table 2. The mean operative time in Retroperitoneoscopic approach was 123 minutes compared to 135 minutes in Open approach. The mean estimated blood loss was $51.47 \mathrm{ml}$ in Retroperitoneoscopic approach compared to $112.07 \mathrm{ml}$ in Open approach. The mean analgesic requirement in terms of morphine equalents - tramadol dose was $34.55 \mathrm{mg}$ in Retroperitoneoscopic approach compared to 85.10 $\mathrm{mg}$ in Open approach. The mean day of oral intake in Retroperitoneoscopic approach was 1.22 days compared to 2.09 days in Open approach. The mean day of ambulation was 1.17 days in Retroperitoneoscopic approach compared to 2.09 days in Open approach. The mean day of drain removal was 2.47 days in Retroperitoneoscopic approach compared to 3.11 days in Open approach. The mean duration of hospital stay was 3.43 days in Retroperitoneoscopic approach compared to 7.18 days in Open approach. Post operative atelectasis was seen in $10 \%(15 / 150)$ of patients of Open group and only $2 \% \quad(3 / 150)$ developed in Retroperitoneoscopic group. The success percentage was 95.3 (143/150) in Retroperitoneoscopic approach compared to $96(145 / 150)$ in Open approach. The mean duration of follow up was 24.06 months in Retroperitoneoscopic approach compared to 23.18 months in Open approach. Success rate and follow up period did not show statistically significant difference between the two groups. Other perioperative data like operative time, blood loss, analgesic requirement, day of oral intake, day of ambulation, day of drain removal, duration of hospital stay and incidence of post operative atelectasis showed statistically significant difference between Retroperitoneoscopic dismembered Pyeloplasty group and Open dismembered Pyeloplasty group ('p' values shown in Table 2).

Table 2: Comparison of perioperative outcome data between Retroperitoneoscopic dismembered Pyeloplasty (RDP) group and Open dismembered Pyeloplasty (ODP) group.

\begin{tabular}{|c|c|c|c|}
\hline & RDP group & ODP group & 'p' value* \\
\hline $\begin{array}{l}\text { Mean operative time- } \\
\text { in minutes (mean } \pm \\
\text { SD) }\end{array}$ & $\begin{array}{l}123.79 \pm \\
32.12\end{array}$ & $135.87 \pm 8.78$ & $<0.0001$ \\
\hline $\begin{array}{l}\text { Mean estimated blood } \\
\text { loss-in ml (mean } \pm \\
\text { SD) }\end{array}$ & $51.47 \pm 16.25$ & $112.07 \pm 20.72$ & $<0.0001$ \\
\hline $\begin{array}{l}\text { Mean analgesic } \\
\text { requirement- } \\
\text { morphine equalents- } \\
\text { tramadol in mg (mean } \\
\pm \text { SD) }\end{array}$ & $34.55 \pm 11.38$ & $85.10 \pm 9.13$ & $<0.0001$ \\
\hline $\begin{array}{l}\text { Mean day of oral } \\
\text { intake (mean } \pm S D)\end{array}$ & $1.22 \pm 0.49$ & $2.09 \pm 0.34$ & $<0.0001$ \\
\hline $\begin{array}{ll}\text { Mean day of } & \text { of } \\
\text { ambulation (mean } & \pm \\
S D \text { ) } & \end{array}$ & $1.17 \pm 0.52$ & $2.09 \pm 0.34$ & $<0.0001$ \\
\hline $\begin{array}{l}\text { Mean day of drain } \\
\text { removal }(\text { mean } \pm S D)\end{array}$ & $2.47 \pm 0.79$ & $3.11 \pm 0.42$ & $<0.0001$ \\
\hline $\begin{array}{l}\text { Mean duration of } \\
\text { hospital stay-in days } \\
\text { (mean } \pm \text { SD) }\end{array}$ & $3.43 \pm 0.94$ & $7.18 \pm 0.82$ & $<0.0001$ \\
\hline $\begin{array}{l}\text { Incidence of post op } \\
\text { atelectasis(in } \\
\text { percentage) }\end{array}$ & 2 & 10 & 0.004 \\
\hline $\begin{array}{ll}\text { Success } & \text { rate(in } \\
\text { percentage) } & \end{array}$ & 95.3 & 96.0 & 0.556 \\
\hline $\begin{array}{l}\text { Mean duration of } \\
\text { follow up-in months } \\
\text { (mean } \pm \text { SD) }\end{array}$ & $24.06 \pm 8.53$ & $23.18 \pm 9.20$ & 0.391 \\
\hline
\end{tabular}

*'p' values calculated using student's t test for quantitative variables and chi square test for qualitative variables -values less than 0.05 were taken as significant. SD- standard deviation 


\section{Discussion}

Open Pyeloplasty has been considered as gold standard procedure for surgical correction of UPJO with success rate more than $90 \%$ until recently laparoscopic Pyeloplasty gained its popularity. Open Pyeloplasty has considerable morbidity of the muscle cutting lumbar incision made ${ }^{[15] ;[16]}$. Over past few years laparoscopic approach gave similar or even better results ${ }^{[5] ;[8] ;[17]}$. Also laparoscopic approach showed several advantages like better cosmetic results, less morbidity, less post operative pain and shorter convalescence ${ }^{[18]}$.

Laparoscopic Pyeloplasty can be classified based on two approaches, transperitoneal and retroperitoneal. Each approach has its own advantages and disadvantages. Although transperitoneal approach has advantages like large working space, better field of vision, disadvantages like abdominal visceral injury, high incidence of post operative ileus, time consuming dissection to reach renal pelvis made most urologist still prefer open approach in recent trends [15];[19]. Retroperitoneoscopic approach has the disadvantages of less working space, limited field of vision and altered anatomical orientation of structures. However several advantages of this technique mentioned below made us to prefer Retroperitoneoscopy as the approach of choice for not only Pyeloplasty but several retroperitoneal conditions in our department. Advantages of Retroperitoneoscopic approach are direct access to pelvis, less dissection to expose pelvi-ureteric junction, minimal risk of intraperitoneal organ injury, exposure of peritoneum to blood, urine and carbon dioxide are avoided, and feasible in patients with previous abdominal surgeries ${ }^{[20]}$.

In our study, operative time for Retroperitoneoscopic approach was significantly less than open approach (123 minutes versus 135 minutes respectively). No significant increase in operative time was noted in retroperitoneoscopic approach compared to open approach in contrast to previous studies ${ }^{[21] ;[22]}$. Operative time in our study was similar to previous published retroperitoneoscopic pyeloplasty studies (ranging from 123 minutes to 140 minutes $)^{[9] ; ~[23] ;[24]}$. The average blood loss was significantly lower in retroperitoneoscopic approach compared to open approach (51.47 $\mathrm{ml}$ versus $112.07 \mathrm{ml})$. Retroperitoneal approach and minimal dissection after Gaur's balloon technique to reach ureteropelvic junction resulted in lesser blood loss. Analgesic usage was calculated in terms of morphine equivalents of tramadol as we use tramadol routinely for post operative analgesia. A significantly less requirement of analgesia in retroperitoneoscopic approach compared to open approach (34.55 mg versus $85.10 \mathrm{mg}$ ) was seen in our study. Less post operative pain in retroperitoneoscopic pyeloplasty was well documented in previous studies ${ }^{\text {[21]; [25] }}$.

In our study, patients with delay in return of bowel sounds and abdominal distension were provisionally diagnosed to have paralytic ileus which was confirmed by imaging. Hence the incidence of postoperative ileus was inversely correlated with the return of bowel sounds and starting of oral intake. The mean day of oral intake was 1.22 days in retroperitoneoscopic group compared to open group with 2.09 days. As we had previously mentioned high incidence post operative ileus is one of the main disadvantage in transperitoneal approach. In our study, 15 patients out of 150 developed postoperative atelectasis in open dismembered Pyeloplasty group (10\%), which was diagnosed based on clinical findings in affected side lung base and chest radiography. Significantly lower number of patients, only 3 out of 150 patients (2\%) developed post operative atelectasis in retroperitoneoscopic group. Large rib cutting flank incision and surgical manipulations near the diseased side lung base were the possible reasons for high incidence of postoperative atelectasis in open dismembered pyeloplasty group. The mean day of drain removal was earlier in retroperitoneoscopic approach compared to open approach. The possible explanations are minimal dissection, lesser blood loss and smaller working space. The patients after retroperitoneoscopic pyeloplasty were ambulated on the very next day after surgery as most of the drawbacks of an open 
muscle cutting surgery were not seen in retroperitoneoscopic approach. The mean duration of hospital stay was 3.43 days in retroperitoneoscopic approach compared to open approach with 7.18 days which was clinically significant. Retroperitoneoscopic approach resulted in minimal functional injury to the patient and short recovery period which lessened their duration of hospital stay considerably compared to open approach. In our study, success was defined as resolution of clinical symptoms, improvement in radiographic appearance of patent ureteropelvic junction and decreased hydronephrosis ${ }^{[10]}$. Success rate after retroperitoneoscopic dismembered pyeloplasty was almost similar to open dismembered pyeloplasty $(95.3 \%$ versus $96 \%$ respectively). Adhering to the basic laparoscopic principles and adequate experience in retroperitoneoscopy made reconstruction of ureteropelvic junction very similar to open approach leading to equivalent success rate. The mean duration of follow up of patients were 36.3 and 28.1 months in retroperitoneoscopic approach and open approach respectively.

In our experience, each step in retroperitoneoscopic dismembered pyeloplasty is getting evolved with increasing learning curve. Reconstruction of ureteropelvic junction which was considered as the technically challenging part of this procedure can be done as good as in the gold standard open technique with experience. Long term follow up of these patients are required to further compare these two techniques in terms of quality of life, long term function of the diseased side and remote complications.

\section{Conclusion}

Retroperitoneoscopic Dismembered Pyeloplasty when compared to Open Dismembered Pyeloplasty has the advantage of shorter hospital stay, reduced analgesia requirement, reduced incidence of atelectasis, early convalescence and equal success rate proving to be the Gold Standard procedure. However, meta-analysis of similar studies worldwide is needed along with prospective component for considering Retroperitoneoscopic Dismembered Pyeloplasty as Gold standard treatment replacing open pyeloplasty in the management of UPJO.

\section{Source of Support: Nil}

Conflict of Interest: None declared.

\section{References}

1. Troxel S, Das S, Helfer E, Nugyen M. Laparoscopy versus dorsal lumbotomy for ureteropelvic junction obstruction repair. $\mathbf{J}$ Urol. 2006;176:1073-76.

2. Schuessler WW, Grune MT, Tecuanhuey LV, Preminger GM. Laparoscopic dismembered pyeloplasty. J Urol. 1993;150:1795-99.

3. Adeyoju AB, Hrouda D, Gill IS. Laparoscopic pyeloplasty: The first decade. BJU Int. 2004;94:264-67.

4. Baldwin DD, Dunbar JA, Wells N, McDougall EM. Single centre comparison of laparoscopic pyeloplasty, Acucise endopyelotomy, and open pyeloplasty. J Endourol. 2003;17:155-60.

5. Janetschek G, Peschel R, Altarac S, Bartsch G. Laparoscopic and retroperitoneoscopic repair of ureteropelvic junction obstruction. Urology. 1996;47(3):311-16.

6. Rassweiler JJ, Teber D, Frede T. Complications of laparoscopic pyeloplasty. World J Urol. 2008;26:539-47

7. Devenport K, Minervini A, Timoney FX., Jr. Our experience with retroperitoneal and transperitoneal laparoscopic pyeloplasty for pelvi-ureteric junction obstruction. Eur Urol. 2005;48(6):973-77

8. Soulie M, Salomon L, Patard JJ, et al. . Extraperitoneal laparoscopic pyeloplasty: a multicentric study of 55 procedures. J Urol. 2001;166(1):48-50

9. Wang X, Zhang Z, Peng N, Liu C. Retroperitoneal laparoscopic versus open dismembered pyeloplasty for ureteropelvic 
junction obstruction. J Xray Sci Technol. 2013;21(3):429-439.

10. Zhang X, Li HZ, Ma X, Zheng $\mathrm{T}$ et al. Retrospective comparison of retroperitoneal laparoscopic versus open dismembered pyeloplasty for ureteropelvic junction obstruction. J Urol. 2006 Sep;176(3):107780.

11. Valla JS, Breaud J, Griffin SJ, Sautot-Vial $\mathrm{N}$ et al. Retroperitoneoscopic vs open dismembered pyeloplasty for ureteropelvic junction obstruction in children. J Pediatr Urol. 2009 Oct;5(5):368-73.

12. Eden CG, Cahill D, Allen JD. Laparoscopic dismembered pyeloplasty: 50 consecutive cases. BJU Int. 2001;88:526-31.

13. Gaur DD: Retroperitoneal laparoscopy: a simple technique of balloon insertion andestablishment of the primary port. Br J Urol.1996;77:458-59.

14. Hinman, F., Jr.: Atlas of Urologic Surgery. Philadelphia: W. B. Saunders Co.,1989:705-709.

15. Tan, B.J., Rastinehad, A.R., Marcovich, R., Smith, A.D., Lee, B.R. Trends in ureteropelvic junction obstruction management among urologists in the United States. Urology. 2005;65:260-64.

16. Brooks JD, Kavoussi LR, Preminger GM, Schuessler WW, Moore RG: Comparison of open and endourologic approaches to the obstructed ureteropelvic junction. Urology. 1995; 46: 791-95.

17. Jarrett TW, Chan DY, Charambura TC, Fugita O, Kavoussi LR. Laparoscopic pyeloplasty: the first 100 cases. J Urol. 2002;167:1253-56.

18. Chen RN, Moore RG, Kavoussi LR. Laparoscopic pyeloplasty. Indications, technique, and long-term outcome. Urol Clin North Am. 1998 May;25(2):323-30.

19. Vijayanand D, Hasan T, Rix D, Soomro N: Laparoscopic transperitoneal dismembered pyeloplasty for ureteropelvic junction obstruction. J Endourol. 2006; 20: 1050-53.
20. Hao, G., Xiao, J., Yang, P. et al, Laparoscopic retroperitoneal dismembered pyeloplasty: single-center experience in China. J Laparoendosc Adv Surg Tech A. 2013;23:38-41.

21. Bonnard A, Fouquet V, Carricaburu E, Aigrain Y, El-Ghoneimi A. Retroperitoneal laparoscopic versus open pyeloplasty in children. J Urol 2005;173:1710-13.

22. Klingler HC, Remzi M, Janetschek G, et al. Comparison of open versus laparoscopic pyeloplasty techniques in treatment of ureteropelvic junction obstruction. Eur Urol. 2003;44:340-45.

23. Moon DA, El-Shazly MA, Chang CM, et al. Laparoscopic pyeloplasty: evolution of a new gold standard. Urology. 2006;67:93236.

24. Rassweiler JJ, Subotic S, Feist-Schwenk M, Sugiono M, Schulze M, Teber D, et al. Minimally invasive treatment of ureteropelvic junction obstruction: Longterm experience with an algorithm for laser endopyelotomy and laparoscopic retroperitoneal pyeloplasty. J Urol. 2007;177:1000-5.

25. Soulie, M., Thoulouzan, M., Seguin, P., Mouly, P., Vazzoler, N., Pontonnier, F. et al, Retroperitoneal laparoscopic versus open pyeloplasty with a minimal incision (comparison of two surgical approaches). Urology. 2001;57:443. 